\title{
Effect of bait density on consumption rates and mortality of subterranean termite Coptotermes curvignathus
}

\author{
Yuliati Indrayani*, Dewi Fatmawati \\ Faculty of Forestry, Tanjungpura University, Jl. Imam Bonjol, Pontianak 78124, West Kalimantan, Indonesia
}

\begin{abstract}
Utilization of baits for controlling termites is achieving high attention in recent year. One of affecting factors of baiting preference of termites including the density of bait. In this study, the effect of bait density on consumption rates and mortality of subterranean termite Coptotermes curvignathus was investigated. Baits prepared by 1:1:1 weight ratio of mixed blended official waste paper, cardboards and cajuput (Melaleuca leucadendra) leaf which were formed into a cube measuring $2 \times 2 \times 1 \mathrm{~cm}$. The baits density were $0.5,0.6,0.7,0.75,0.8,1.0 \mathrm{gr} / \mathrm{cm}^{3}$. No choice and multiple choice tests were conducted with five replications. Clear plastics cup measuring diameter $6 \mathrm{~cm}$ and $12 \mathrm{~cm}$ were employed for no choice test and multiple choice tests respectively. Fifty workers and five soldiers of $C$. curvignathus were used for no choice test, while 150 workers and 15 soldiers were tested in the multiple choices test. The results indicated that bait with lower density had a better consumption rates to $C$. curvignathus. The influence of bait density on termite mortality was also reported, since there is a relationship between consumption rates and termite mortality which is contrary to the general toxicity test. The percentage of consumption rates was still lower therefore further research is indispensible on reformulation of the baits.
\end{abstract}

Keywords: Bait density, consumption rates, subterranean termites Coptotermes curvignathus, termite control, termite mortality

Received: 07 April 2019 Revised: 01 June 2019 Accepted: 20 June 2019

\section{Introduction}

Termites are not only known as damaging wood material but also as decomposers in natural ecosystem. In this case, termites are playing an important role in the conversion of cellulotic wastes into organic nutrients (Haritos et al., 1993; Itakura et al., 2006; Muin \& Arif, 2017). In term of termites as pest for wooden building materials, much more attentions have been addressed to the development of termite control for the protection of wooden constructions. In recent years, more attention is given to the development of environmentally friendly termite control systems, one of them is bait systems.

A baiting system is one of the environmentally friendly methods for controlling termite attacks. The bait system, aimed at suppressing the termite population, essentially consists of food matrix with a slow-acting toxicant being delivered to the whole termite colony through direct feeding and secondary transfer. Some active ingredients used for termite bait such as hexaflumuron, triflumuron, and others have been investigated by several researchers (Grady et al. 2008, Renato et al. 2017, Khalid and Denis. 2018, Garry 2017, Abid et al. 2015, A Gambetta et al. 2000).

It is believed that the source and formulation of the cellulose and toxic materials can affect the effectiveness of a bait system which can be determined through the termite consumption and food transfer efficiency among

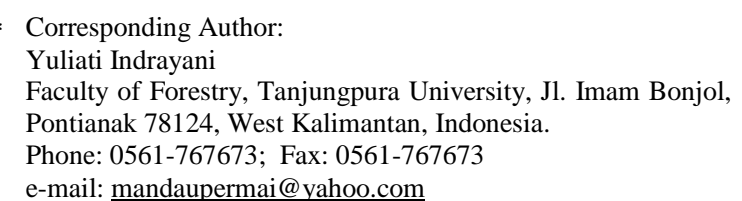

termites in their colony. Our previous field study on source and formulation of the bait matrix show that termite activities can reduce soil density and increase COrganic matter (Indrayani et al., 2017). However, the effectiveness in terms of bait density has not been studied so far. There is a relationship between bait density and consumption rate of termites since the mechanical characteristics of termite feeding are determined by the hardness of the material eaten. This statement is supported by Owoyemi et al (2013), who states that wood density is one of the factors of wood protection against termite attacks.

Materials such as solid wood, sawdust, cardboard, paper, and powdered cellulose are commonly used as bait matrices and monitoring devices because of their high cellulose contents. The current research was designed to evaluate the potential of using organic wastes such as waste paper and toxic parts of plants as a bait matrix formulation for the control of termite $C$. curvignathus in various densities through consumption rates and mortality of termites.

\section{Methods}

\section{Materials}

Two types of waste paper, cardboard (inner part) and official paper and cajuput (Melalueca leucadendra) leaf were used as bait materials. Both of that waste paper was soaked in water for 24 hours then blended. Leaves were collected from an area around Pontianak City, West Kalimantan, Indonesia in December 2018. The leaves were then air dried inside a room for three days (Indrayani et al., 2017) before being milled using hammer mill. Use of M. leucadendra leaf were based on the results of previous studies which indicating potential attractant properties of the M. leucadendra leaf crude extract as well 
as slow-acting toxic properties to termites (Indrayani et al. 2016-2017). Subterranean termite Coptotermes curvignathus which is obtained from secondary forest around Pontianak City were use as test organisms.

\section{Bait Preparation}

Bait formulation was produced by mixing equal quantities (1:1:1 weight ratio) of cardboard, office paper, and leaves based on their oven-dried weights and were formed into a cube measuring $2 \mathrm{~cm} \times 2 \mathrm{~cm} \times 1 \mathrm{~cm}$. The baits were prepared with various densities that are $0.5,0.6,0.7,0.75$, $0.8,1.0 \mathrm{gcm}^{-3}$. All baits were then oven dry at $40^{\circ} \mathrm{C}$ for 24 hours for determining the initial weight before testing.

\section{Termite Bioassay}

In this study, two types of testing methods were carried out namely no-choice test and multiple choice test. The multiple choice test method was carried out to determine which bait was preferred by termites while the no-choice test method was used to find out how much bait was eaten by termites. No-choice and multiple choice tests were conducted with five replications in this study. Clear plastics cup measuring diameter $6 \mathrm{~cm}$ and $12 \mathrm{~cm}$ were employed for no choice test and multiple choice tests respectively. $60 \mathrm{~g}$ sterile sea sand moistened with 20 $\mathrm{ml}$ distilled water for no choice test and $120 \mathrm{~g}$ sterile sea sand moistened with $40 \mathrm{ml}$ distilled water were placed at the bottom of cup. One bait was put into the cup for no choice test, while for multiple choice test all of baits were put into the cup. Fifty workers and five soldiers of $C$. curvignathus were used for no choice test, while 150 workers and 15 soldiers were tested in the multiple choices test. All test units were kept in the dark room at $28 \pm 2^{\circ} \mathrm{C}$ and $80 \% \mathrm{RH}$ and was observed for three weeks. The effect of bait density was determined through consumption rates and mortality of the termite. Each treatment consisted of five replicates. Termite bioassays were presented in Fig. 1 and 2.

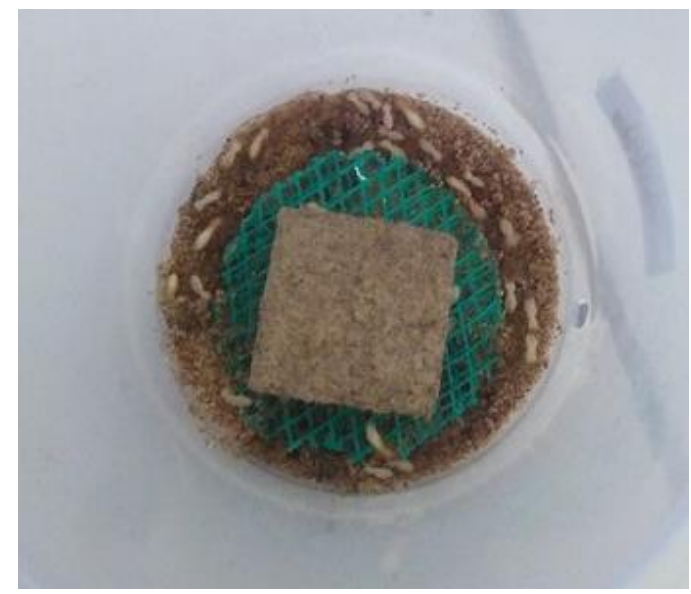

Figure 1. No-choice test.

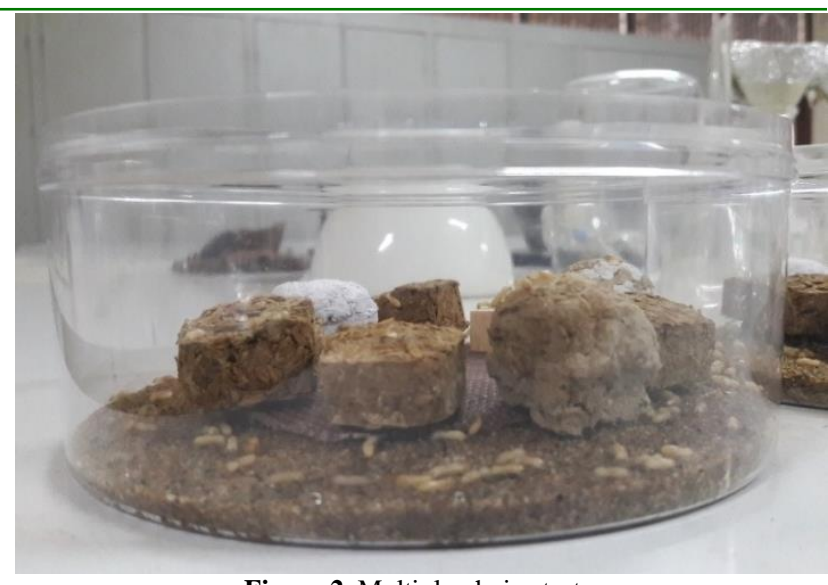

Figure 2. Multiple-choice test.

\section{Data Analysis}

Data were statistically analyzed by Variable Analysis in a factorial design, and Tukey Analysis was used for comparison of the mean values (Gaspersz, 1994).

\section{Results}

\section{No-Choice Test}

The no-choice test showed that density influence weight loss of bait after three weeks exposure to subterranean termite $C$. curvignathus. Figure 3 shows the average consumption rate values ranging from $1.68 \%$ and $6.18 \%$ respectively. The highest density bait $\left(1.0 \mathrm{gcm}^{-3}\right)$ had the lowest weight loss value with an average weight loss of $1.68 \%$, whereas low density bait $\left(0.5 \mathrm{gcm}^{-3}\right)$ caused highest an average weight loss value of $6.18 \%$. The rest density bait, $0.6,0.7,0.75$, and $0.8 \mathrm{gcm}^{-3}$ had weight loss value of $5.48,3.34,2.98$, and $2.21 \%$ respectively. This finding clarified that bait with low density had a better consumption rates to termite $C$. curvignathus. Bait with density $0.5 \mathrm{gcm}^{-3}$ show higher consumption rates consequently resulting higher weight loss of bait, on the other hand, bait with density $1.0 \mathrm{gcm}^{-3}$ cause lower weight loss (Fig. 3). Nevertheless, bait with density 0.5 and $0.6 \mathrm{gcm}^{-3}$ has no statistically significant difference $(P>0.5)$. Fig. 3 also indicate that there is no statistically significant difference among density $0.7,0.75,0.8$ and 1.0 $\mathrm{gcm}^{-3}$ as well $(P>0.5)$, yet, significant difference was observed between the two groups (significant at $P<0.05$ ).

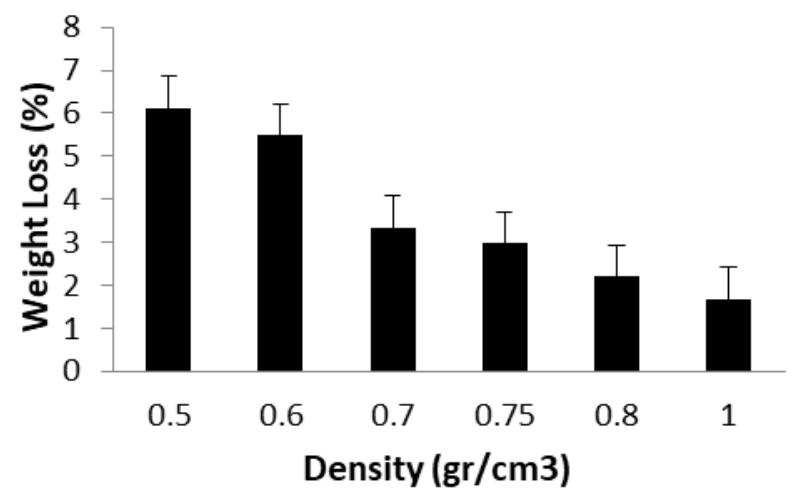

Figure 3. Relationship of density of bait to weight loss in no-choice test. 
In case of termite mortality, a similar result was observed as weight loss as well, Figure 4 shows that as the density bait increases, termite mortality decreases. Highest density bait $1.0 \mathrm{gcm}^{-3}$ showed lowest average termite mortality value at $15.11 \%$. On the contrary, lowest density bait $0.5 \mathrm{gcm}^{-3}$ resulted in highest average termite mortality value reach of $100 \%$. The rest of the baits with density $0.6,0.7,0.75$, and $0.8 \mathrm{gcm}^{-3}$ caused termite mortality of $87.27,50.30,15.62$, and $18.18 \%$ respectively. Bait with density 0.5 and $0.6 \mathrm{gcm}^{-3}$ show not statistically significant difference $(P>0.5)$ resulting in higher mortality of termite among density with average value of $100 \%$ and $87.27 \%$ respectively. Figure 4 also describe there is no statistically significant difference among density $0.75,0.8$, and $1.0 \mathrm{gcm}^{-3}(P>0.5)$, whereas density 0.7 $\mathrm{gcm}^{-3}$ show statistically significant difference to density $0.5,0.6 \mathrm{gcm}^{-3}$ and $0.75,0.8,1.0 \mathrm{gcm}^{-3}$. In general Fig. 4 revealed that higher weight loss is followed by higher termite mortality, this is contrary to the toxicity testing which were higher weight loss is followed by lower termite mortality.

\section{Multiple-Choice Test}

The weight loss value in multiple choice test tends to show similar results to no-choice test. The average weight loss values in multiple choice test were ranging from 3.13 $\%$ and $5.81 \%$ respectively. Lower density bait $0.5 \mathrm{grcm}^{-3}$ resulted in higher average weight loss value of $5.81 \%$ while higher density bait $1.0 \mathrm{gcm}^{-3}$ had lower average weight loss value of $3.13 \%$ (Figure 5). Others density bait $0.6,0.7,0.75$, and $0.8 \mathrm{gcm}^{-3}$ had average weight loss 3.42 , $2.17,2.63,1.75$, and $0.84 \%$ respectively. Figure 5 also demonstrate that there is no statistically significant difference among density $0.6,0.7,0.75,0.8,1.0 \mathrm{gcm}^{-3}$ $(P>0.5)$ but statistically significant difference was noted between those densities and density $0.5 \mathrm{gcm}^{-3}$ (significant at $P<0.05$ ).

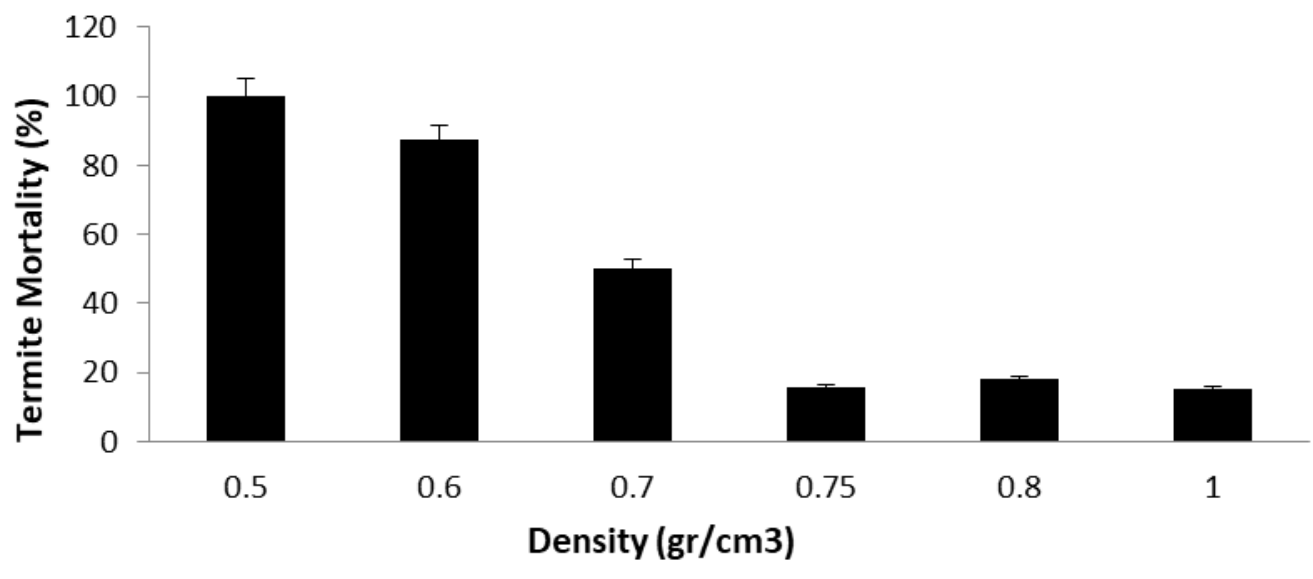

Figure 4. Relationship of density of bait to termite mortality in no-choice test.

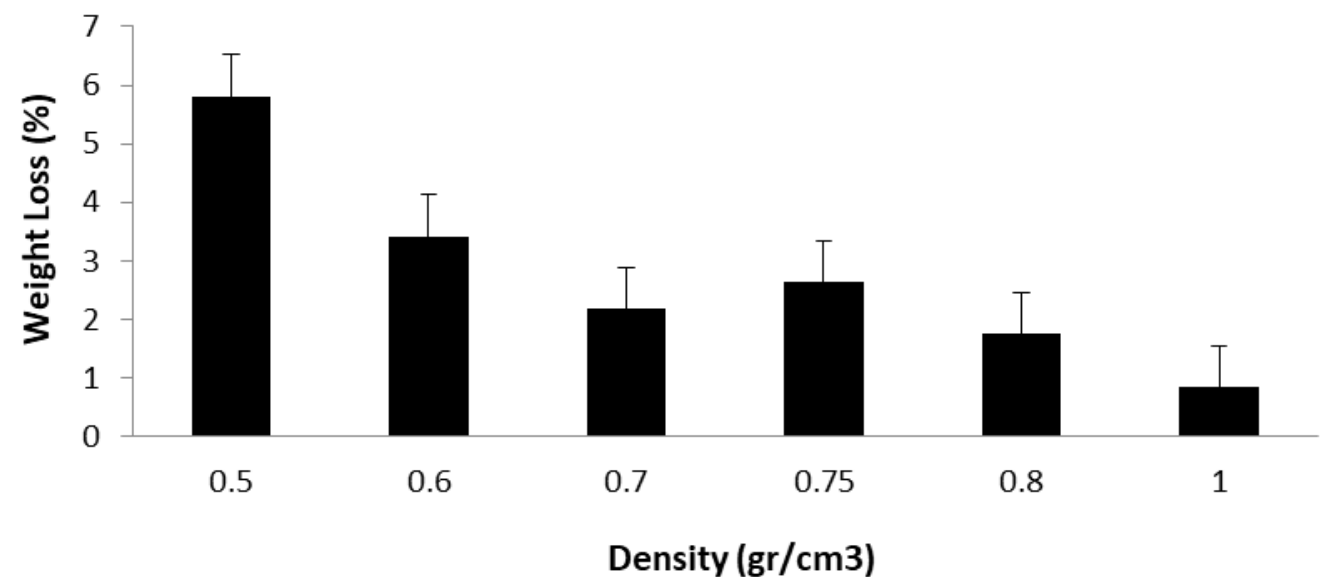

Figure 5. Relationship of density of bait to weight loss in multiple-choice test. 


\section{Discussion}

Present study revealed that the density of bait influence consumption rate and mortality of termites. Figs. 3 and 5 show that both no-choice and multiplechoice test show the similar tendency that is low density had a better consumption rates to termite $C$. curvignathus resulting higher of weight loss. The weight loss value and density bait shown in Figures 3 and 5 revealed that weight loss and density bait are inversely related. From these results, it could be said that lower density bait is more promising as bait for termite compared to higher density bait. It is understandable since it has been stated previously that the mechanical characteristics of termite feeding are determined by the hardness of the material eaten. Additionally, Walters (1981) said that wood degraded by termites by mean of biting and chewing. This highlights that degradable bait was noted at low density bait with weight loss of $6.11 \%$ (no-choice test) and 5.81 $\%$ (multiple choice test) as against high density with weight loss of $1.68 \%$ (no-choice test) and $0.84 \%$ (multiple choice test). The results of this study indicating that besides the cellulose content in the material, eating preferences of termites are also influenced by the hardness of the material they eat. Study concerning correlation between consumption rates and wood specific gravity (Esenther, 1977) and wood density (Peralta et al., 2004) were support this finding. They were reported that higher wood specific gravity as well wood density cause lower consumption rates of termites.

A similar result was also reported by Owoyemi et al. (2013) who stated that the high density species had the lowest weight loss values.

Other research conducted by Arango et al. (2006) express that extractives of wood are play an important role as termite deterrent, and making it more resistant to termite attack. So, in addition except the cellulose content and material density, the consumption rates of termites were also depends on the extractive compound.

Consumption rates associated with termite mortality. In term of bait investigation, higher consumption rates are followed by higher termite mortality (Figs. 3, 4, and 5). Density bait $0.5 \mathrm{gcm}^{-3}$ caused termite mortality to reach $100 \%$. This can be explained because low density bait was more preferred by termites, consequently bait containing slow-acting chemical compound from $M$. leucadendra were responsible for termite mortality.This might be caused bait used in this study consist of waste paper as matrix and M. leucadendra as both attractant and slow-acting chemical (Indrayani et al., 2016-2018). GCMS analysis of extract $M$. leucadendra leaf conducted by Indrayani et al. (2017) show that extract mainly contain of eugenol compound which is known have both attractant and slow-acting properties. This is contrary to the general toxicity test, which lower consumption rates resulting higher termite mortality.

In conclusion, this study highlights that density of bait were found to be effective indicated through consumption rates and termite mortality in the laboratory test. These results indicate that among six density levels observed in this study, the higher consumption rates and mortality of termites was notes on density $0.5 \mathrm{gcm}^{3}$. Since the percentage of consumption rates was still lower, therefore future research is indispensable, particularly, concerning reformulation of the baits matrix for the development of a termite bait system.

\section{Acknowledgment}

The authors gratefully acknowledges to the Directorate General of Higher Education of Indonesia and Tanjungpura University for financial support.

\section{References}

Arango, R. A., Green, F., Hintz, K., Lebow, P. K., \& Miller, R. B. (2006). Natural durability of tropical and native woods against termite damage by Reticulitermes flavipes (Kollar). Journal of International Biodeterioration and Biodegradation, 57, 146-150.

Abid, F., Maid, Z., Muhammad, S., Maazullah, K., \& Tahir, B.S. (2015). Evaluation of Boric Acid as a slow-acting toxicant against subterranean termites (Heterotermesi and Odontotermes). Journal of Entomology and Zoology Studies 3(1), 213-216.

A., Gambetta, V., Zaffagnini, \& E. D., Capua. (2000). Use of Hexaflumuron baits against subterranean termites for protection of historical and article structures: Experiment carried out in selected test. Journal of Cultur Heritage 1(3), 207-216.

Esenther, G. R. (1977). Nutritive supplement method to evaluate resistance of natural or preservative wood to subterranean termites. Journal of Economic Entomology, 70(3), 341-346.

Grady, J. G., James, W. A., \& Roger, E. G. (2008). Efficacy of commercial termite baiting systems for management of subterranena termites (Isoptera: Rhinotermitidae) in texas. Sociobiology, 51(2), 333-362.
Garry, A. W. (2017). Efficacy of Bistrifluron termite bait on Coptotermes lacteus (Isoptera: Rhinotermitidae) in Southern Australia. Journal of Economic Entomology O(0),1291-1299.

Gaspersz, V. (1994). Experimental design method. Publisher Armico, Jakarta (in Indonesian).

Haritos, V. S., French, J. R. J., \& Ahokas, J. T. (1993). The metabolism and comparative elimination of chlorinatedbiphenyl congeners in termites. Chemosphere, 26, 1291-1299.

Itakura, S., Okuda, J., Utagawa, K., Tanaka, H., \& Enoki, A. (2006) Nutritional value of two subterranean termite species, Coptotermes formosanus Shiraki and Reticulitermes speratus (Kolbe) (Isoptera: Rhinotermitidae). Japan Journal Entomology and Zoology, 17(3), 107-115.

Indrayani, Y., Muin, M., \& Yoshimura, T. (2016). Crude extract of two different leaf plant species and their responses against subterranean termite Coptotermes formosanus. Journal of Nusantara Bioscience, 8(2), 226-231.

Indrayani, Y., Muin, M., \& Yoshimura, T. (2017). Diversity of tropical plants and their attractant properties for subterranean termite Coptotermes curvignathus. Journal Biodiversitas, 18(4), 1353 1357.

Indrayani, Y., Muin, M., Adilla, C., \& Yoshimura, T. (2018). Attractiveness of subterranean termite Coptotermes formosanus to plant leaf extract. Journal of Biodiversitas, 19(3), 1176-1180.

Khalid, Z. R., \& Denis, J. W. (2018). Comparative efficacy of three bait toxicants against the subterranean termite Reticulitermes san- 
tonensis (Isoptera/Blattoidea: Rhinotermitidae). Biomedical Journal of Scientific \& Technical Research 11(3), 8536-8559.

Muin, M., \& Arif, A. (2017). Conversion of waste paper-based bai formulation for biogenic production by termites in tropical land. The Journal of Solid Waste Technology and Management, 43(1), 75-81.

Owoyemi, J. M., Olaniran, S. O., \& Aliyu, D. I. (2013). Effect of density on the natural resistance of ten selected Nigerian wood species to subterranean termites. Journal of Pro Ligno, 9(1), 32-40.

Peralta, R. C. G., Menezes, B., Carvalho, A. G., \& Aguiar-Menezes, E. (2004). Wood consumption rates of forest species by subterraneantermites (Isoptera) under field conditions. Sociedade de Investigações Florestais, 28, 283-289.

Renato, R., Paola, L., Nan-Yao, S., \& Michael, K.R. (2017). Field evaluation of potential control strategies against the invasive Eastern subterranean termite (Isoptera: Rhinotermitidae) in Chile. Journal of Economic and Entomology 100(4), 1391-1399.

Walters, C.B. (1981). The chemical treatment of wood for end use. In wood, its structure and properties. R., F., Hangar, (Ed.) Pennsylvania State Universitry. 